\title{
PENGARUH INDEPENDENSI DEWAN PENGAWAS SYARIAH DALAM MEWUJUDKAN GOOD CORPORATE GOVERNANCE UNTUK MENINGKATKAN KINERJA BMT
}

\author{
Iin Emy Prastiwi \\ STIE-AAS Surakarta \\ Email: iinemyprastiwi24@gmail.com
}

\begin{abstract}
This study aims at determining the contribution of the independence Sharia Supervisory Board and Good Corporate Governance individually and simultaneously to the performance of the BMT in Sukoharjo and Karanganyar. This study was a survey research with a quantitative approach. The populations in this study were the manager and supervisor of BMT. The sampling technique was a convenience sampling method possible. Samples taken as many as 30 data were spread at 9 BMT in Sukoharjo, and 6 BMT in Karanganyar. Data were taken by using a questionnaire and the analysis of the balance sheet and profit and loss. Testing of instruments used validity test, reliability test, test of sub-structures I, II, and III and then are analyzed by Path Analysis. The results in this study are: (1) the independency of the Sharia Supervisory Board affects significantly positive on the Good Corporate Governance of $65.4 \%$. (2) the independence of the Sharia Supervisory Board affects significantly negative on the performance of 0,244 , (3) Good Corporate Governance affects significantly positive on the performance of 1,125 . (4) The independency of the Sharia Supervisory Board and Good Corporate Governance affect significantly positive on the performance of $88.1 \%$.
\end{abstract}

Keywords: Independency, Sharia Supervisory Board, Good Corporate Governance, Performance of BMT, Path Analysis

\section{Pendahuluan}

Perkembangan Lembaga Keuangan Mikro Syariah semakin pesatdari tahun ke tahun. Anggraeni et al (2013) menyatakan BMT sebagai salah satu Lembaga Keuangan Syariah non Bank, sangat mendukung permodalan terhadap sektor UMKM di Indonesia.Semakin bertambahnya jumlah BMT yang berdiri, memberikan ruang kepada masyarakat untuk lebih leluasa memilih BMT yang bagus kinerjanya. Persaingan antar lembaga keuangan syariah baik BMT maupun bank syariah yang semakin ketat, menuntut masing-masing lembaga harus memiliki kinerja yang bagus dan sesuai syariah.

Potensi BMT yang semakin berkembang pesat, selain kinerja BMT yang menjadi perhatian, tidak lupa jati diri yang JURNAL ILMIAH EKONOMI ISLAM VOL. 03 NO. 01, MARET 2017 paling pokok dari BMT adalah identitas keislamannya (Hendriani, 2012). Dalam hal ini, sangat diperlukan adanya bagian khusus dari BMT yang mengawasi operasionalnya agar tidak melanggar prinsip-prinsip syariah, yaitu adanya Dewan Pengawas Syariah. Menyadari peran Dewan Pengawas Syariah sangat penting, agar masyarakat terus yakin dan percaya menggunakan jasa BMT, maka Dewan Pengawas Syariah dalam melakukan tugasnya haruslah memiliki independensi yang bagus. Oleh karena berkaitan dengan kepercayaan masyarakat, terutama tentang kesyariahan bank syariah, maka keanggotaan Dewan Pengawas Syariah haruslah bersifat independen (tidak memihak), objektif dan jujur (Prasetyoningrum, 2010:4).

Untuk meningkatkan kinerja BMT selain pengawasan syariah, ada sisi lain yang 
harus diperhatikan yaitu bermacam-macam risiko yang harus dihadapi dalam menjalankan aktivitasnya. Oleh karena itu penerapan tata kelola perusahaan yang baik (Good Corporate Governance) sangat diperlukan untuk menghindari berbagai risiko tersebut. Penerapan Good Corporate Governance pada BMT merupakan wujud pertanggungjawaban BMT terhadap masyarakat bahwa BMT sudah dikelola dengan baik dan profesional berdasarkan prinsip kehati-hatian (prudent) dengan tidak mengabaikan aturan syariah.

Dari uraian latar belakang di atas, maka dalam penelitian ini, penulis ingin meneliti tentang "Pengaruh Independensi Dewan Pengawas Syariah dalam Mewujudkan Good Corporate Governance untuk Meningkatkan Kinerja Baitul Maal wat Tamwil (Studi Kasus pada BMT di Sukoharjo, dan Karanganyar)”.

\section{Kinerja Baitul Maal Wat Tamwil}

Kinerja dalam bahasa Inggris adalah performance yang mempunyai arti pelaksanaan. Menurut Zarkasyi (2008:48) kinerja perusahaan merupakan sesuatu yang dihasilkan oleh suatu organisasi dalam periode tertentu dengan mengacu pada standar yang ditetapkan.Sedangkan penilaian kinerja pada perbankan dikembangkan dengan menggunakan rasio-rasio keuangan (Asrori, 2014). Menurut Mink dalam Thoin (2015) bahwa kinerja merupakan suatu kondisi yang harus diketahui serta dikonfirmasikan untuk para pihak yang bersangkutan, untuk melihat tingkat pencapaian hasil suatu instansi dihubungkan dengan visi serta mengetahui dampak positif dan negatif dari suatu kebijakan-kebijakan operasionalnya. Individu yang memiliki kinerja yang tinggi memiliki beberapa karakteristik khusus. Diantara karakteristik tersebut: (a) individu yang selalu berorientasi prestasi, (b) memiliki percaya diri, (c) berperngendalian diri, (d) kompetensi.

Pedoman Penilaian Kesehatan Koperasi Jasa Keuangan Syariah dan Unit Jasa Keuangan Syariah diatur dalam Peraturan Menteri Negara Koperasi dan Usaha Kecil dan Menengah Republik Indonesia No.35.3/Per/M.KUKM/X/2007 tentang Pedoman Penilaian Kesehatan Koperasi Jasa Keuangan Syariah dan Unit Jasa Keuangan Syariah yang disebutkan dalam Bab III pasal 5 sebagai berikut:

"Ruang Lingkup Penilaian Kesehatan KJKS dan UJKS koperasi meliputi penilaian terhadap beberapa aspek sebagai berikut:

1. Permodalan

2. Kualitas Aktiva Produktif

3. Manajemen

4. Efisiensi

5. Likuiditas

6. Kemandirian dan Pertumbuhan

7. Jatidiri Koperasi

8. Prinsip Syariah"

Namun, penilaian kesehatan dalam penelitian ini menggunakan pedoman versi PINBUK, yaitu ada enam aspek yang menjadi indikator kesehatan BMT. Keenam aspek tersebut yaitu permodalan, kualitas aktiva produktif, likuiditas, efisiensi usaha, rentabilitas, kemandirian dan keberlanjutan (Aslichan, 2009:199).

\section{Persepsi Independensi DPS}

\section{A. Dewan Pengawas Syariah}

Dewan Pengawas Syariah adalah dewan yang melakukan pengawasan terhadap prinsip syariah dalam kegiatan usaha bank syariah yang dalam menjalankan fungsinya bertindak secara independen (Muhammad, 2011:27). 
Dewan Pengawas Syariah merupakan salah satu bagian penting dari Lembaga Keuangan Syariah. Peran utama Dewan Pengawas Syariah adalah mengawasi jalannya operasional Lembaga Keuangan Syariah sehari-hari, agar selalu sesuai dengan ketentuan-ketentuan syariah. Menurut Tho'in (2016) bahwa bank syariah adalah bank yang beroperasi sesuai dengan prinsip-prinsip syariah Islam. Karena bank syariah termasuk pula dalam lembaga keuangan syariah. DPS harus membuat pernyataan yang biasanya dibuat secara berkala (setiap tahun) bahwa Lembaga Keuangan Syariah yang diawasinya benar-benar telah berjalan sesuai dengan ketentuan syariah (Syakir Sula, 2004: 541-542).

BMT memiliki Dewan Pengawas Syariah adalah Peraturan Meneg Koperasi dan UKM RI No.35.2/ PER/M.KUKM/X/2007 Tentang Pedoman Standar Operasional Manajemen KJKS dan UJKS Koperasi, dalam BAB I Ketentuan Umum, pasal 1 ayat 8 menyebutkan:

"Dewan Pengawas Syariah pada KJKS dan UJKS Koperasi adalah dewan yang dipilih oleh koperasi yang bersangkutan berdasarkan keputusan rapat anggota dan beranggotakan alim ulama yang ahli dalam syariah yang menjalankan fungsi dan tugas sebagai pengawas syariah pada koperasi yang bersangkutan dan berwenang memberikan tanggapan atau penafsiran terhadap fatwa yang dikeluarkan Dewan Syariah Nasional.”

\section{B. Persepsi}

Menurut Kotler dan Keller (2012) persepsi adalah proses bagaimana seseorang menyeleksi, mengatur, dan mengintepretasikan masukan-masukan informasi untuk menciptakan gambaran keseluruhan yang berarti. Masing-masing individu akan memandang objek yang sama namun mempersepsikannya berbeda. Adapun faktor yang mempengaruhi persepsi seseorang adalah karateristik orang yang dipersepsi dan faktor situasional.

\section{Independensi DPS}

Menurut Kasim, et al (2013:224) indepedensi adalah sikap seseorang dimana dalam sudut pandang, pendapat, maupun kesimpulan yang disampaikannya tidak bergantung pada pengaruh dan tekanan dari pihak yang berkepentingan. Sedangkan menurut Halim (2015: 48) independensi merupakan suatu sikap mental yang dimiliki auditor untuk tidak memihak dalam melakukan audit. Dalam AAOIFI dan IFSB menuntut agar Dewan Pengawas Syariah harus independen dari lembaganya dan tidak tunduk pada manajemen lembaga tersebut. Dewan Pengawas Syariah tidak hanya bertindak untuk kepentingan bank, tetapi juga investor. Dewan Pengawas Syariah juga harus bertindak sesuai dengan kepentingan investor yang berminat dan konsisten dengan investasi berbasis syariah. Dalam hal ini Dewan Pengawas Syariah diasumsikan sebagai "saluran transformasional" antara hukum agama dan investor (Casper, 2012: 10).

Seperti halnya auditor, seorang Dewan Pengawas Syariah harus bersikap independen. Independensi meliputi dua hal yaitu Independensi dalam pemikiran dan penampilan.Independensi dalam pemikiran merupakan sikap mental yang memungkinkan pernyataan pemikiran 
yang tidak dipengaruhi oleh hal-hal yang dapat mengganggu pertimbangan profesional, yang memungkinkan seseorang individu untuk memiliki integritas dan bertindak secara objektif, serta menerapkan skeptisisme profesional. Sedangkan Independensi dalam penampilan merupakan sikap yang menghindari tindakan atau situasi yang dapat menyebabkan pihak ketiga (pihak yang rasional dan memiliki pengetahuan mengenai semua informasi yang relevan, termasuk pencegahan yang diterapkan) meragukan integritas, objektivitas, atau skeptisisme profesional dari anggota tim (Jusup, 2014:139).

Menurut Karim (1990) dalam Prasetyoningrum (2010:29) ada sejumlah persamaan mendasar antara peran Dewan Pengawas Syariah dengan akuntan publik. Sehingga teori-teori akuntan publik dapat digunakan untuk Dewan Pengawas Syariah. Menurut Kode Etik Akuntan Publik, seorang auditor harus mematuhi 5 prinsip dasar yang harus dipegang, yaitu terdiri dari integritas, objektivitas, kompetensi dan kehati-hatian profesional, kerahasiaan, dan perilaku profesional.

\section{Good Corporate Governance}

Good Corporate Governance menurut PBI No.11/33/PBI/2009 tentang pelaksanaan Good Corporate Governance bagi Bank Umum Syariah dan Unit Usaha Syariah adalah suatu tata kelola Bank yang menerapkan prinsip-prinsip keterbukaan (transparency), akuntabilitas (accountability), pertanggungjawaban

(responsibility), profesional (professional), dan kewajaran (fairness). Namun untuk prinsip Good Corporate Governance pada perbankan syariah ditambah prinsip spiritualitas (spirituality) (Nasirwan dan Utomo, 2006:51).

Menurut Mr. Wolfensohn (Presiden Bank Dunia) sebagaimana dikutip oleh Rivai (2009:106) tujuan dari Good Corporate Governance adalah untuk mewujudkan keadilan bagi seluruh stakeholders melalui penciptaan transparansi dan akuntabilitas yang lebih besar.Secara umum para ahli dan pelaku perbankan syariah sepakat bahwa prinsip-prinsip pokok Good Corporate Governance yang dikembangkan oleh international standard setter dan dipraktekkan oleh lembaga keuangan konvensional hampir seluruhnya bersifat sejalan dengan nilai-nilai Islami sehingga sesuai untuk diimplementasikan pada perbankan syariah. Pengaturan Good Corporate Governance pada bank syariah diperlukan sebagai suatu jaminan bahwa pemenuhan prinsip syariah pada bank syariah bisa dilakukan dengan baik. Jaminan pemenuhan prinsip syariah bisa dilakukan baik melalui penetapan aturan tentang struktur governance bank syariah yang menjamin tersedianya fungsi pengawasan tentang aspek kesyariahan (Nasirwan dan Utomo, 2006: 30$33)$. 


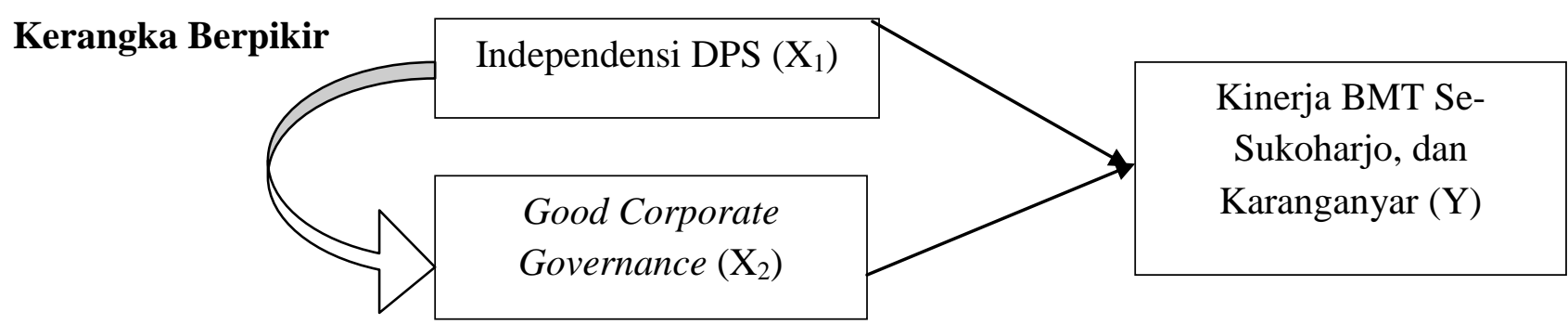

Gambar 1

Kerangka Berpikir

Adapun hipotesis dalam penelitian ini adalah sebagai berikut:

Hipotesis 1

Diduga ada pengaruh signifikan antara independensi Dewan Pengawas Syariah terhadap Good Corporate Governance pada BMT di Sukoharjo dan Karanganyar; Hipotesis 2

Diduga ada pengaruh signifikan antara independensi Dewan Pengawas Syariah terhadap kinerja pada BMT di kabupaten Sukoharjo dan Karanganyar;

Hipotesis 3

Diduga ada pengaruh signifikan antara Good Corporate Governance terhadap kinerja pada BMT di kabupaten Sukoharjo dan Karanganyar

Hipotesis 4

Diduga ada pengaruh signifikan antara independensi DPS dan Good Corporate Governance secara bersama-sama terhadap kinerja pada BMT di Sukoharjo dan Karanganyar.

\section{Metode Penelitian}

Penelitian ini merupakan penelitian survei dengan pendekatan kuantitatif. Variabel dalam penelitian ini adalah independensi DPS $\left(\mathrm{X}_{1}\right)$, Good Corporate Governance $\left(\mathrm{X}_{2}\right)$, dan Kinerja pada BMT (Y).

Teknik pengambilan sampel denganmotode convenience sampling. Populasi dalam penelitian ini adalah adalah manajer dan supervisor BMT yang menggunakan jasa dan laporan DPS yang tersebar di kabupaten Sukoharjo, dan Karanganyar. Sampel dalam penelitian ini diambil sebanyak 30 data yang tersebar di 9 BMT di Sukoharjo, dan 6 BMT di Karanganyar.

\section{Metode Pengumpulan Data}

Pengumpulan data dalam penelitian ini, dengan dokumentasi, observasi dan studi pustaka. Data diambi dengan menggunakan metode kuesioner dan analisis laporan neraca dan laba rugi.

\section{Metode Analisis Data}

a. Uji Validitas

Kuesioner dikatakan valid jika pertanyaan mampu mengungkapkan sesuatu yang akan diukur dengan kuesioner tersebut. Pengujian validitas ini menggunakan signifikansi Pearson Correlation yaitu dengan cara menghitung korelasi antara nilai yang diperoleh dari pertanyaanpertanyaan. Apabila signifikansi Pearson Correlation yang didapat memiliki nilai dibawah 0,05 berarti data yang diperoleh adalah valid (Ghozali, 2005:45).

b. Uji Reliabilitas

Uji reabilitas dilakukan untuk mendapatkan ketepatan (keterandalan atau keajegan) alat pengukur data (instrumen) yang digunakan. Uji reliabilitas instrumen dilakukan dengan uji statistik cronbachalpha $(\alpha)$.Pengukuran reliabilitas mempunyai kisaran 0-1 dengan nilai antara 0,6-0,7 yang merupakan batas 
terendah untuk penerimaan. Idealnya nilai ini diatas 0,7 atau 0,8 (Sarwono, 2013:247)

\section{c. Method of Succesive Interval (MSI)}

Salah satu syarat path analysis ini digunakan adalah data berskala interval dan rasio. Teknik transformasi yang paling sederhana adalah Method of Succesive Interval (MSI).Method of Succesive Interval (MSI) yaitu metode untuk meningkatka skala data penelitian yang berskala ordinal menjadi berskala interval sehingga regresi bisa dilakukan (Riduwan dan Kuncoro, 2013).

Langkah-langkah Method of Succesive Interval (MSI) adalah sebagai berikut (Riduwan dan Kuncoro, 2013:30):

a) Perhatikan setiap butir jawaban responden dari angket yang disebarkan;

\section{$N S=\frac{(\text { Density at Lower Limit })-(\text { Density at Upper Limit })}{(\text { Area Below Upper Limit })-(\text { Area Below Lower }}$}

h) Tentukan nilai trasnformasi dengan rumus:

d. Path Analysis b) Pada setiap butir ditentukan berapa orang yang mendapat skor 1,2,3,4 dan 5 yang disebut sebagai frekuensi;

c) Setiap frekuensi dibagi dengan banyaknya responden dan hasilnya disebut proporsi;

d) Tentukan proporsi kumulatif dengan jalan menjumlahkan nilai proporsi secara berurutan perkolom skor;

e) Gunakan Tabel Distribusi Normal (tabel $\mathrm{Z}$ ), hitung nilai $\mathrm{Z}$ untuk setiap proporsi kumulatif yang diperoleh;

f) Tentukan nilai tinggi densitas untuk setiap nilai $\mathrm{Z}$ untuk setiap nilai yang diperoleh (dengan menggunakan tabel Tinggi Densitas);

g) Tentukan nilai skala dengan menggunakan rumus

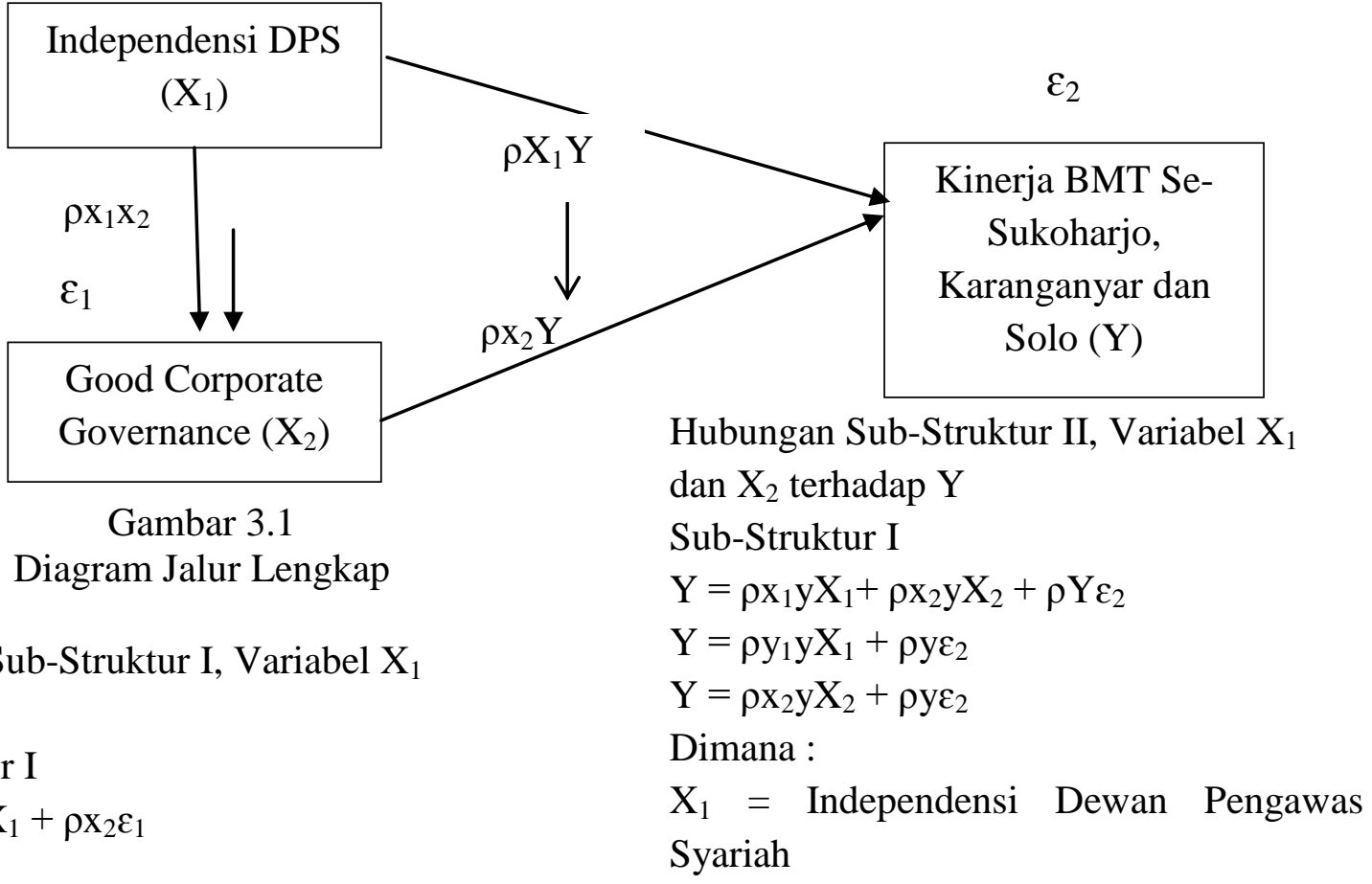

Hubungan Sub-Struktur I, Variabel $\mathrm{X}_{1}$

Untuk pengujian hipotesis, menggunakan analisis jalur (path analysis). Model persamaan untuk menguji hipotesis dengan analisis jalur dapat dibuat melalui persamaan struktur sebagai berikut:

terhadap $\mathrm{X}_{2}$

Sub-Struktur

$Y_{2}=\rho x_{1} x_{2} X_{1}+\rho x_{2} \varepsilon_{1}$
Syariah 


$$
\begin{aligned}
& \mathrm{X}_{2}=\text { Good Corporate Governance } \\
& \mathrm{Y}=\text { Kinerja BMT } \\
& \varepsilon=\text { error }
\end{aligned}
$$

\section{Hasil Penelitian}

Penelitian ini mengambil responden manager dan supervisor BMT di kabupaten Sukoharjo dan Karanganyar. Peneliti memilih manajer dan supervisor sebagai responden dalam penelitian ini karena diharapkan manajer dan supervisor bisa memberikan persepsinya terhadap independensi Dewan Pengawas Syariah dan memberikan informasi mengenai pelaksanaan Good Corporate Governance pada BMT-nya masing-masing.

Penyebaran kuesioner dimulai pada tanggal 1 Juni 2016 sampai 30 Juni 2016 dan dilakukan ke 13 BMT di Sukoharjo, 13 BMT di Karanganyar. BMT yang dijadikan objek penelitian adalah BMT yang sudah memiliki Dewan Pengawas Syariah dan bersedia memberikan laporan neraca dan laba ruginya. Masing-masing BMT diberikan 2 buah kuesioner untuk diisi manager dan supervisor. Data jumlah penyebaran kuesioner pada BMT responden sebagai berikut:

Tabel 1

Data Sampel Penelitian

\begin{tabular}{|c|c|c|c|}
\hline & Keterangan & $\begin{array}{c}\text { Jumlah } \\
\text { Kuesioner } \\
\text { yang } \\
\text { Disebar }\end{array}$ & Persentase \\
\hline 1 & $\begin{array}{l}\text { Jumlah Kuesioner } \\
\text { yang tidak kembali }\end{array}$ & 10 & $19,23 \%$ \\
\hline 2 & $\begin{array}{l}\text { Jumlah Kuesioner } \\
\text { yang tidak dapat } \\
\text { diolah }\end{array}$ & 12 & $23,08 \%$ \\
\hline 3 & $\begin{array}{l}\text { Jumlah Kuesioner } \\
\text { yang dapat diolah }\end{array}$ & 30 & $57,69 \%$ \\
\hline $\mathbf{4}$ & $\begin{array}{l}\text { Total Kuesioner } \\
\text { yang disebar }\end{array}$ & $\mathbf{5 2}$ & $\mathbf{1 0 0 \%}$ \\
\hline
\end{tabular}

Sumber: Data primer diolah, 2016

Berdasarkan tabel 1 dapat dijelaskan bahwa dari 52 kuesioner yang disebar, ada 42 kuesioner yang kembali dan hanya 30 kuesioner yang bisa diolah. Adapun data
BMT responden yang mengembalikan kuesioner dan dapat diolah adalah sebagai berikut:

Tabel 2

\begin{tabular}{|c|c|c|c|}
\hline Nama BMT & Manager & $\begin{array}{c}\text { Supervis } \\
\text { or }\end{array}$ & Lainnya \\
\hline $\begin{array}{l}\text { Kabupaten Sukoharjo: } \\
\text {. BMT Al Firdaus } \\
\text {. BMT Amanah Insani } \\
\text { 3. BMT Fadhila Sentosa } \\
\text { 1. BMT Bina Umat } \\
\text { Mandiri } \\
\text {. BMT Hasanah } \\
\text { क. BMT Al A'la } \\
\text {. BMT Nur Insan Mandiri } \\
\text { BMT Emas Rejeki } \\
\text { Abadi } \\
\text { BMT Amanah Ummah } \\
\text { Kabupaten Karanganyar: } \\
\text { 10. BMT Kube } \\
\text { Colomadu Sejahtera } \\
\text { 11. BMT Atunnisa } \\
\text { 12. BMT Al Kautsar } \\
\text { 13. BMT Bina Insan } \\
\text { Mandiri } \\
\text { 14. BMT Alfa Dinar } \\
\text { 15. BMT Karanganyar Kube } \\
\text { Karang }\end{array}$ & $\begin{array}{l}1 \\
1 \\
1 \\
1 \\
1 \\
1 \\
1 \\
1 \\
1\end{array}$ & $\begin{array}{l}1 \\
- \\
- \\
1 \\
- \\
- \\
- \\
- \\
1\end{array}$ & $\begin{array}{l}- \\
1 \\
1 \\
- \\
1 \\
1 \\
1 \\
1 \\
-\end{array}$ \\
\hline Total & 15 & 7 & 8 \\
\hline
\end{tabular}

Rincian Pengembalian kuesioner yang dapat diolah

Dari data responden, didapatkan bahwa bahwa responden yang berjenis kelamin pria berjumlah 21 orang atau $70 \%$ dan wanita berjumlah 9 orang atau 30\%. Lalu responden berdasarkan jabatan didapatkan yang berprofesi sebagai manager berjumlah 15 orang atau $50 \%$, sebagai supervisor berjumlah 7 orang atau 23,33\%, sebagai karyawan lainnya berjumlah 8 orang atau $26,67 \%$. Untuk responden berdasarkan usia didapatkan yang berumur 19-30 tahun berjumlah 9 orang atau 30\%, untuk responden yang berumur 31-40 tahun berjumlah 8 orang atau $26,67 \%$, dan untuk responden yang berumur diatas 40 tahun berjumlah 13 orang atau $43,33 \%$.

Sedangkan untuk responden berdasarkan pendidikan didapatkan responden yang lulusan SMA berjumlah 3 orang atau $10 \%$, responden lulusan D3 berjumlah 5 orang atau $16,67 \%$, responden lulusan $\mathrm{S} 1$ 
berjumlah 21 orang atau $70 \%$, responden lulusan S2 berjumlah 1 orang atau 3,33\%. Untuk responden berdasarkan lamanya bekerja didapatkan bahwa responden yang telah bekerja 1-3 tahun berjumlah 5 orang atau $16,67 \%$, responden yang bekerja lebih dari 3 tahun berjumlah 25 orang atau 83,33\%.

Dalam penelitian ini untuk mengukur independensi Dewan Pengawas Syariah, dan Good Corporate Governance menggunakan skala likert 5 poin mulai dari sangat tidak setuju, tidak setuju, netral, setuju dan sangat setuju. Sedangkan untuk mengukur kinerja ke 15 BMT di Sukoharjo dan Karanganyar peneliti menggunakan analisis kesehatan BMT versi PINBUK berpedoman pada penelitian Aslichan, Hubeis dan Sailah (2009: 199-202).Karena keterbatasan data, maka peneliti hanya menghitung rasio-rasio tingkat permodalan (CAR), efisiensi (efisiensi inventaris dan biaya), likuiditas (rasio kas/ cash ratio), rentabilitas (ROA dan ROE).

Pengukuran kinerja BMT didasarkan pada rasio-rasio permodalan, efisiensi, likuiditas dan rentabilitas. Caranya dengan menghitung dari laporan neraca dan laba rugi BMT dan memberi skor 5 tingkat, mulai dari sangat rendah, rendah, cukup, tinggi, dan sangat tinggi. Berdasarkan analisis data neraca dan laba rugi, dari 15 BMT ada 1 BMT atau $6,67 \%$ tergolong sangat kurang sehat, 5 BMT atau 33,33\% tergolong kurang sehat, 6 BMT atau 40\% tergolong cukup sehat, 2 BMT atau $13,33 \%$ tergolong sehat, dan 1 BMT atau $6,67 \%$ tergolong sangat sehat. Kebanyakan BMT responden adalah cukup sehat dan kurang sehat, hal ini perlu diperhatikan BMT agar kepercayaan masyarakat tetap terjaga dan pengawasan audit terhadap laporan keuangan BMT lebih ditingkatkan dan lebih ketat.Setiap kesulitan dan permasalahan harus segera diprediksi agar segera dicari solusi untuk pemecahan masalah.Sehingga hal-hal yang tidak diharapkan bisa dihindari sedini mungkin.

Hasil uji hipotesis pertama menunjukkan bahwa Independensi Dewan Pengawas Syariah berpengaruh signifikan terhadap Good Corporate Governance pada BMT di kabupaten Sukoharjo dan Karanganyar. Besarnya $\mathrm{R}$ square sebesar 0,654 yang berarti besarnyakontribusi pengaruh sebesar 0,654 atau sebesar 65,4\% dengan arah positif. Semakin tinggi sikap independensi Dewan Pengawas Syariah dalam pengawasan syariah, maka semakin baik juga penerapan Good Corporate Governance pada BMT. Dalam hal ini, independensi Dewan Pengawas Syariah sangat diperlukan agar aktivitas operasional BMT senantiasa dalam koridor kepatuhan syariah.Dengan demikian semakin baik kuantitas dan kualitas pengawasan oleh DPS, maka semakin baik juga penerapan Good Corporate Governance pada BMT. Hasil ini sesuai dengan hipotesis kedua, yang berarti hasil analisis statistik menunjukkan adanya hubungan yang signifikanindependensi Dewan Pengawas Syariah terhadap Good Corporate Governance pada BMT.

Hasil uji hipotesis kedua menunjukkan bahwa independensi Dewan Pengawas Syariah berpengaruh signifikan dengan arah negatif terhadap kinerja BMT di kabupaten Sukoharjo dan Karanganyar. Besarnya kontribusi pengaruh independensi Dewan Pengawas Syariah sebesar $0,244^{2}$ atau 0,059. Hal ini berarti semakin tinggi independensi Dewan Pengawas Syariah dalam pengawasan syariah, maka semakin turun kinerja BMT. BMT dalam kondisi tertentu merasa ada tekanan antara keharusan mematuhi prinsipprinsip syariah dengan tuntutan untuk meningkatkan aspek profitabilitas sesuai yang 
ditargetkan. Hal ini disebabkan terkadang masyarakat tidak terlalu mementingkan kepatuhan syariah dan lebih cenderung memilih yang praktis dalam masalah keuangan. Namun BMT harus tetap memprioritaskan profit yang halal dan thayib menjadi hal yang utama.

$$
\text { Hasil uji hipotesis ketiga }
$$

menunjukkan bahwa Good Corporate Governance berpengaruh signifikan terhadap kinerjapada BMT di kabupaten Sukoharjo dan Karanganyar. Besarnya kontribusi pengaruh Good Corporate Governance sebesar 1,125 atau 1,266 dengan arah positif. Hal ini berarti semakin tinggi Good Corporate Governance, maka semakin tinggi kinerja BMT. Mekanisme Good Corporate Governance pada manajemen BMT dapat meminimalkan berbagai risiko, baik risiko kredit, risiko likuiditas, risiko operasional, risiko reputasi dan sebagainya. Hal inidapat meningkatkan kepercayaan investor dan masyarakat sekitar, sehingga dapat meningkatkan kinerja BMT

Hasil uji hipotesis keempat menunjukkan bahwa independensi Dewan Pengawas Syariah dan Good Corporate Governance secara bersama-sama berpengaruh signifikan terhadap kinerja pada BMT di kabupaten Sukoharjo dan Karanganyar.Besarnya $\mathrm{R}$ square sebesar 0,881 yang berarti besarnyakontribusi pengaruh independensi Dewan Pengawas Syariah dan Good Corporate Governance secara bersama-sama sebesar 0,881 atau $88,1 \%$. Sisanya $11,9 \%$ dipengaruhi oleh variabel lain yang tidak disebutkan dalam model, misalnya komite audit.Hasil ini sesuai dengan hipotesis kelima, yang berarti hasil analisis statistik menunjukkan adanya hubungan yang signifikan dan simultan antaraindependensi DPS dan Good Corporate Governance terhadap kinerja BMT.
Namun besarnya kontribusi pengaruh Good Corporate Governance terhadap kinerja sebesar 1,125 dengan arah positif, dan kontribusi pengaruh independensi Dewan Pengawas Syariah terhadap kinerja sebesar 0,244 dengan arah negatif. Sedangkan pengaruh independensi Dewan pengawas Syariah terhadap kinerja BMT melalui Good Corporate Governance sebesar $0,666^{2}$ atau 0,4436 atau $44,36 \%$. Hal ini bisa dijelaskan bahwa peran Dewan Pengawas Syariah secara langsung dalam aktivitas dan operasional BMT, maka hal ini justru akan membuat pihak manajemen BMT menjadi tertekan. Peran DPS sebaiknya mengacu pada imlementasi prinsip-prinsip Good Corporate Governance perbankan syariah

\section{Kesimpulan}

Kesimpulan dari hasil analisis data dalam penelitian ini adalah hasil uji statistik hipotesis pertama menunjukkan bahwa independensi DPS berpengaruh signifikan terhadap Good Corporate Governance pada BMT di kabupaten Sukoharjo dan Karanganyar. Hasil uji statistik hipotesis kedua menunjukkan bahwa independensi DPS berpengaruh signifikan dengan arah negatif terhadap kinerja BMT di kabupaten Sukoharjo dan Karanganyar. Hasil uji statistik hipotesis ketiga menunjukkan bahwa Good Corporate Governance berpengaruh signifikan dengan arah positif terhadap kinerja pada BMT di kabupaten Sukoharjo dan Karanganyar. Hasil uji statistik hipotesis keempat menunjukkan bahwa independensi DPS dan Good Corporate Governance secara bersama-sama berpengaruh signifikan terhadap kinerja pada BMT di kabupaten Sukoharjo dan Karanganyar. 


\section{Daftar Pustaka}

Anggraeni, Lukytawati. et al. 2013. Akses UMKM Terhadap Pembiayaan Mikro Syariah dan Dampaknya Terhadap Perkembangan Usaha: Kasus BMT Tadbiirul Ummah, Kabupaten Bogor. Jurnal Muzara'ah. (Vol).1, No. 1, 2013. Bogor: Departemen Ekonomi, FE dan Manajemen IPB.

Aslichan, et.al. 2009. Kajian Penilaian Kesehatan dalam Rangka Mengevaluasi Kinerja Lembaga Keuangan Mikro Syariah Baitul Maal wat Tamwil : Kasus BMT Bina Ummat Sejahtera Lasem Rembang. Jurnal Manajemen IKM (Vol).4 No.2

Asrori.2014. Implementasi Islamic Corporate Governance dan Implikasinya Terhadap Kinerja Bank Syariah. Jurnal Dinamika Akuntansi. (Vol).6, No.1. Semarang: FE, Universitas Negeri Semarang

Ghozali, Imam. 2005. Aplikasi Analisis Multivariate dengan Program SPSS. Edisi 3. Semarang: Badan Penerbit Universitas Diponegoro.

Halim, Abdul. 2015. Auditing I: Dasar-dasar Audit Laporan Keuangan. Yogyakarta: Unit Penerbit dan Percetakan Sekolah Tinggi Ilmu Manajemen YKPN.

Hendriani, Maria.2012. Peran UMKM dalam Perekonomian Indonesia.

Jusup, Al. Haryono. 2014. Auditing: Pengauditan Berbasis ISA. Yogyakarta: Sekolah Tinggi Ilmu Ekonomi YKPN.

Kasim, Nawal, et al. 2013.Comparative Analysis on AAOIFI, IFSB, and BNM Shari'ah Governane Guidelines.International Journal of Bussines and Social Science.(Vol).4 No. 15. Malaysia: Faculty of Accountancy, Universiti Teknologi MARA Shah Alam.

Kotler, Philip dan Keller, Kevin Lane.2012. Marketing Management.Edisi ke 14.

Muhammad. 2011. Audit dan Pengawasan Syariah pada Bank Syariah. Yogyakarta: UII Press.

Nasirwan dan Utomo, Setiawan Budi.2006. Good Corporate Governance Bank
Syariah.Jakarta: Direktorat Perbankan Syariah, Bank Indonesia.

Peraturan Menteri Negara Koperasi dan Usaha Kecil dan Menengah Republik Indonesia No.35.3/Per/M.KUKM/X/2007 tentang Pedoman Penilaian Kesehatan Koperasi Jasa Keuangan Syariah dan Unit Jasa Keuangan Syariah.

Peraturan Bank Indonesia No.11/33/PBI/2009 tentang pelaksanaan Good Corporate Governance bagi Bank Umum Syariah dan Unit Usaha Syariah

Riduwan, dan Kuncoro, Engkos Achmad.2013. Cara Menggunakan dan Memakai Path Analysis (Analisis Jalur).Bandung: Alfabeta. Cetakan kelima.

Rivai, H. Veithzal et.al.2009. Ekonomi Syariah: Konsep, Praktek dan Penguatan Kelembagaannya. Semarang: Pustaka Rizki Putra

Sarwono, Jonathan. 2013. StatistikMultivariatAplikasiuntukRisetdan Skripsi.Yogyakarta: Andi Yogyakarta.

Syakir Sula, Muhammad. 2004. Asuransi Syariah (Life and General): Konsep dan Sistem Operasional. Jakarta: Gema Insani.

Tho'in, Muhammad. 2015. Analisis Laporan Keuangan Dalam Mengukur Kinerja Keuangan Pada Baitul Maal Wat Tamwil (BMT) Tekun Boyolali. Jurnal Ilmiah Ekonomi Islam, LPPM STIE AAS Surakarta. Vol. 1 No. 3, November 118133.

Tho'in, Muhammad. 2016. Kompetensi Sumber Daya Bank Syariah Berdasarkan Prinsip-prinsip Syariah Islam (Studi Kasus Pada BNI Syariah di Surakarta). Jurnal Ilmiah Ekonomi Islam, LPPM STIE AAS Surakarta. Vol. 2 No. 3, November 158-171.

Zarkasyi, Moh. Wahyudin.2008. Good Corporate Governance pada Badan Usaha Manufaktur, Perbankan dan Jasa Keuangan Lainnya. Bandung: Alfabeta. 